\title{
Water activity in polyol/water systems: new UNIFAC parameterization
}

\author{
C. Marcolli and Th. Peter \\ Institute for Atmospheric and Climate Science, ETH Zurich, Switzerland \\ Received: 1 February 2005 - Published in Atmos. Chem. Phys. Discuss.: 14 March 2005 \\ Revised: 11 May 2005 - Accepted: 25 May 2005 - Published: 17 June 2005
}

\begin{abstract}
Water activities of a series of polyol/water systems were measured with an AquaLab dew point water activity meter at $298 \mathrm{~K}$. The investigated polyols with carbon numbers from $n=2-7$ are all in liquid state at room temperature and miscible at any molar ratio with water. In aqueous solutions with the same molar concentration, the diols with lower molecular weight lead to lower water activities than those with higher molecular weights. For diols with four or more carbon atoms, the hydrophilicity shows considerable differences between isomers: The 1,2-isomers - consisting of a hydrophilic and a hydrophobic part - bind less strongly to water than isomers with a more balanced distribution of the hydroxyl groups. The experimental water activities were compared with the predictions of the group contribution method UNIFAC: the model predictions overestimate the water activity of water/polyol systems of substances with two or more hydroxyl groups and can not describe the decreased binding to water of isomers with hydrophobic tails. To account for the differences between isomers, a modified UNIFAC parameterization was developed, that allows to discriminate between three types of alkyl groups depending on their position in the molecule. These new group interaction parameters were calculated using water activities of alcohol/water mixtures. This leads to a distinctly improved agreement of model predictions with experimental results while largely keeping the simplicity of the functional group approach.
\end{abstract}

\section{Introduction}

Organic species are emitted into the atmosphere by a variety of natural and anthropogenic sources. They account for up to $50 \%$ of the total fine aerosol mass at continental mid-latitudes (Saxena and Hildemann, 1996) and for up to

Correspondence to: C. Marcolli

(claudia.marcolli@env.ethz.ch)
90\% in tropical forested areas (Yamasoe et al., 2000; Roberts et al., 2002). The amount of water absorbed by aerosol particles can be significantly altered by the presence of organics (Saxena et al., 1995; Saxena and Hildemann, 1997). Conversely, gas/particle partitioning of semivolatile species is influenced by the presence of water in particles (Griffin et al., 2003). To tackle these interdependences, thermodynamic models are required that describe gas/particle partitioning and water activity (Bowman and Melton, 2004). The wide variety of organic species present in the ambient aerosol can only be handled by models that parameterize functional groups rather than individual compounds. The most common group contribution method for organic substances is UNIFAC (Fredenslund et al., 1975, 1977). Although it has been shown that the performance of UNIFAC is not satisfactory for predicting water activities of mixtures containing multifunctional organic species (Saxena and Hildemann, 1997; Peng et al., 2001; Ming and Russell, 2002), it is commonly used to describe gas/particle partitioning of semivolatile organic species and water (Pun et al., 2002; Cai and Griffin, 2003; Griffin et al., 2003; Erdakos and Pankow, 2004). Ming and Russell $(2002,2004)$ have therefore developed an improved parameterization to model the influence of organic compounds in affecting droplet number densities in fog.

This study investigates more closely how the performance of UNIFAC depends on the number and the position of functional groups. This is done for a large variety of alcohols including monofunctional as well as polyfunctional ones. Polyfunctional alcohols - so called polyols - together with polyethers have been identified by HNMR as a main class of the water-soluble organic fraction of atmospheric aerosols (Decesari et al., 2000, 2001). Various individual polyols and carbohydrates have been observed in biomass burning samples (Graham et al., 2002; Gao et al., 2003; Claeys et al., 2004, Simoneit et al., 2004). The hydroxyl group therefore can be considered as one of the most important functional groups of organic aerosol constituents. A variety of mono-

(C) 2005 Author(s). This work is licensed under a Creative Commons License. 
Table 1. UNIFAC volume $\left(R_{k}\right)$ and surface area $\left(Q_{k}\right)$ parameters for subgroup $k$ (from Hansen et al., 1991).

\begin{tabular}{cccc}
\hline Main group & Subgroup $k$ & $R_{k}$ & $Q_{k}$ \\
\hline $\mathrm{CH}_{n}(n=0,1,2,3)$ & $\mathrm{CH}_{3}$ & 0.9011 & 0.848 \\
& $\mathrm{CH}_{2}$ & 0.6744 & 0.540 \\
& $\mathrm{CH}$ & 0.4469 & 0.228 \\
$\mathrm{OH}$ & $\mathrm{C}$ & 0.2195 & 0 \\
$\mathrm{H}_{2} \mathrm{O}$ & $\mathrm{OH}$ & 1.0000 & 1.200 \\
& $\mathrm{H}_{2} \mathrm{O}$ & 0.9200 & 1.400 \\
\hline
\end{tabular}

and polyfunctional alcohols are commercially available covering a large number of chain lengths and isomers. The focus of this study is on polyols that are present as liquids at room temperature and miscible at any molar ratio with water. This allows the measurement of water activities of polyol/water bulk samples over the whole composition range. The experimental data is compared with UNIFAC predictions and used together with vapour-liquid equilibrium data of alcohols at the boiling temperature to develop a new improved UNIFAC parameterization.

\section{Experimental methods}

The water activities, $a_{w}$, were measured using an AquaLab water activity meter (Model 3TE, Decagon devices, USA). This instrument applies the chilled mirror technology to determine the dewpoint temperature of air equilibrated with the sample. In addition, infrared thermometry pinpoints the sample temperature. Therefore, accurate measurements are not dependent on precise thermal equilibrium. An internal temperature control allows to have a temperature-stable sampling environment from $15-40^{\circ} \mathrm{C}$. For all measurements, the volatile sample block available as an accessory to the instrument was used. With this sample block, the water activity in the presence of other semivolatile components can be determined. Experimental errors for the volatile sample block are $\pm 0.015 a_{w}$. To correct for instrument drifts and offset, the performance of the sample block was frequently controlled and readjusted with reference samples. All measurements were performed at $298 \mathrm{~K}$. The substances were purchased from Sigma-Aldrich in the best available purity. For glycerol, ethanediol, 1,2-, and 1,3-propanediol as well as 1,3-, 1,4-, and 2,3-butanediols the purity was above $99 \%$, for 1,4-pentanediol it was 99\%, for 1,2-butanediol and 2,4pentanediol $\geq 98.0 \%$, for 1,2 - and 2,5 -hexanediol $\geq 97.0 \%$, for 1,2- and 1,5-pentanediol 96\%, and for 1,2,4-butanetriol and 1,7 -heptanediol $\geq 95 \%$. The substances were used without further purification. The water/polyol mixtures were prepared by mass percent with MilliQ water using an analytical balance.

\section{UNIFAC group contribution method}

The UNIFAC group contribution method (Fredenslund et al., 1975,1977 ) is a broadly used tool for the prediction of liquidphase activity coefficients parameterized for a wide range of structural groups (Hansen et al., 1991). In the UNIFAC model, the activity coefficients of a molecular component $i$ $\left(\gamma_{i}\right)$ in a multicomponent mixture are expressed as the sum of two contributions: a combinatorial part $(C)$, accounting for size and shape of the molecule and a residual part $(R)$, a result of inter-molecular interactions

$$
\ln \gamma_{i}=\ln \gamma_{i}^{C}+\ln \gamma_{i}^{R} \text {. }
$$

The water activity is calculated as

$a_{w}=\gamma_{w} x_{w}$,

where $x_{w}$ is the mole fraction of water and $\gamma_{w}$ is the water activity coefficient accounting for the non-ideality of the mixture. For an ideal mixture $\left(\gamma_{w}=1\right)$, the water activity is simply the mole fraction of water.

The combinatorial part of UNIFAC uses the pure component properties such as volumes and surface areas to account for the excess entropic part of the activity coefficients

$$
\ln \gamma_{i}^{C}=\ln \frac{\Phi_{i}}{x_{i}}+\frac{z}{2} q_{i} \ln \frac{\Theta_{i}}{\Phi_{i}}+\ell_{i}-\frac{\Phi_{i}}{x_{i}} \sum_{j} x_{j} \ell_{j}
$$

where

$$
\Phi_{i}=\frac{r_{i} x_{i}}{\sum_{j} r_{j} x_{j}} ; \quad \Theta_{i}=\frac{q_{i} x_{i}}{\sum_{j} q_{j} x_{j}}
$$

and

$\ell_{i}=\frac{z}{2}\left(r_{i}-q_{i}\right)-\left(r_{i}-1\right)$

with

$r_{i}=\sum_{k} v_{k}^{(i)} R_{k} ; \quad q_{i}=\sum_{k} v_{k}^{(i)} Q_{k}$.

In these equations, $x_{i}$ is the mole fraction of component $i$, $v_{k}^{(i)}$ is the number of groups of type $k$ in molecule $i$, and $z$ is the lattice coordination number, a constant set equal to ten (Fredenslund, 1975). The group volume and surface area parameters $R_{k}$ and $Q_{k}$ are based on the work of Bondi (1968).

The residual part of the activity coefficient is given by

$$
\ln \gamma_{i}^{R}=\sum_{k} v_{k}^{(i)}\left[\ln \Gamma_{k}-\ln \Gamma_{k}^{(i)}\right]
$$

where $\Gamma_{k}$ is the group residual activity coefficient in the mixture and $\Gamma_{k}^{(i)}$ the one in a reference liquid containing only molecules of type $i$. The residual activity coefficients are calculated as

$$
\ln \Gamma_{k}=Q_{k}\left[1-\ln \left(\sum_{m} \Theta_{m} \Psi_{m k}\right)-\sum_{m}\left(\Theta_{m} \Psi_{k m} / \sum_{n} \Theta_{n} \Psi_{n m}\right)\right]
$$



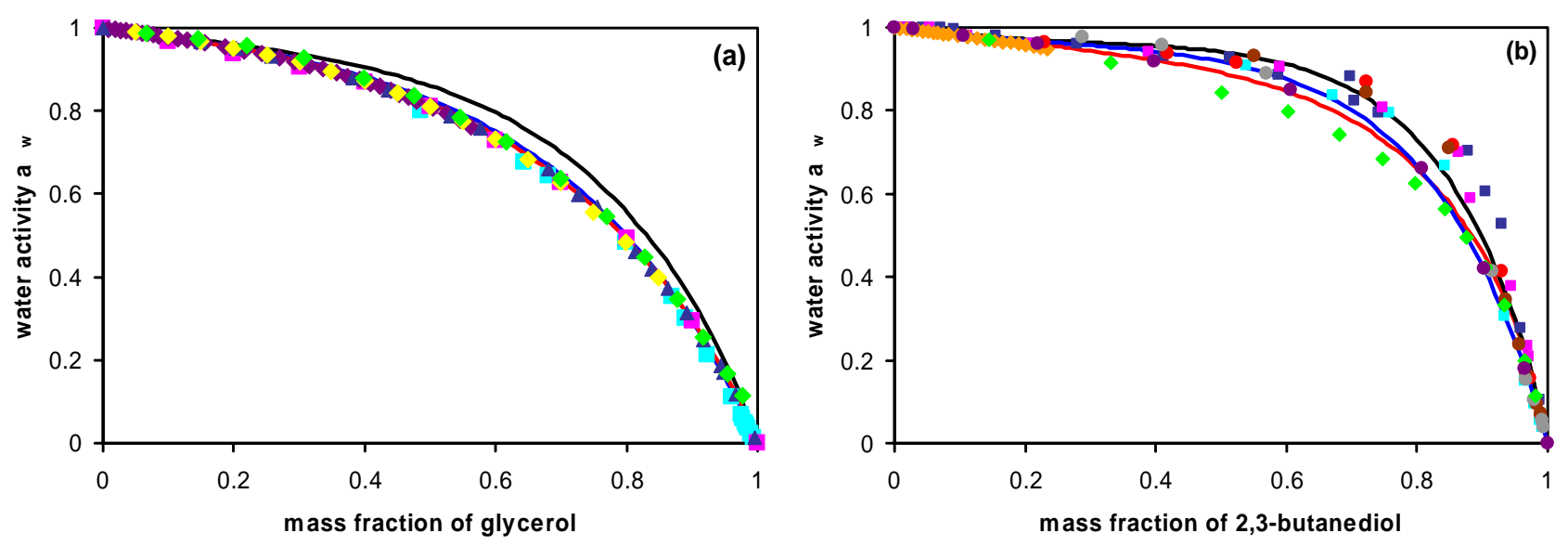

Fig. 1. Water activity of (a) glycerol/water and (b) 2,3-butanediol/water mixtures. Squares: vapour-liquid equilibrium measurements at constant pressures from $750-760 \mathrm{mmHg}\left(100-290^{\circ} \mathrm{C}\right)$, filled circles: vapour liquid equilibrium measurements at constant pressures from 200-600 mmHg $\left(60-180^{\circ} \mathrm{C}\right)$, triangle: vapour-liquid equilibrium data at constant temperature at $25^{\circ} \mathrm{C}$, all data taken from Gmehling and Onken (1977, 2003) and Gmehling et al. (1988), different colors indicate different measurement series; diamonds: water activity measurements at $25^{\circ} \mathrm{C}$ (yellow: Ninni et al. (2000, only glycerol); purple: Scatchard et al. (1938, only glycerol); orange: Borghesani et al. (1989, only 2,3-butanediol); green: this study). Lines: UNIFAC predictions at $25^{\circ} \mathrm{C}$ (black: Hansen et al., 1991; blue: Ming and Russell, 2002; red: using the new parameters from this study).

with

$\Theta_{m}=\frac{Q_{m} X_{m}}{\sum_{n} Q_{n} X_{n}} ; \quad \Psi_{m n}=\exp \left[\frac{-a_{m n}}{T}\right]$

In these expressions, $\Theta_{m}$ is the surface area fraction of group $m, X_{m}$ the mole fraction of group $m$ in the mixture, and $\Psi_{m n}$ the interaction parameter between the groups $m$ and $n$. $\Psi_{m n}$ is temperature dependent and a function of the group interaction parameter $a_{m n}$.

For this study, literature values for group volume and surface area parameters $R_{k}$ and $Q_{k}$ as well as for the group interaction parameters $a_{m n}$ are taken from Hansen et al. (1991). The values used for the investigated alcohols are given in Tables 1 and 2 .

\section{Results and discussion}

\subsection{Water activity measurements}

Table 3 lists the measured water activities for the investigated polyol/water systems. Only a part of the polyols could be purchased in an anhydrous quality. The water activity $a_{w}$ of the different polyols before the addition of water varied between 0 and 0.125 . Based on these values, the water content was estimated to be between 0 and $1.5 \mathrm{wt} \%$ for the different liquids. The compositions of the water/polyol mixtures were therefore corrected to include the water which was present in the compounds as purchased. Such a correction was necessary for glycerol, 1,2-butanediol, all pentanediols, the hexanediols, the heptanediol, as well as 1,2,4-butanetriol.
For some of the investigated polyol/water mixtures, water activity data is already available in the literature. Figure 1 shows a comparison of the water activity from this study and literature data for glycerol and 2,3-butanediol. For glycerol/water, water activity has been determined by vapourliquid equilibrium measurements under isobaric and isothermal conditions at the boiling temperature (Gmehling and Onken, 1977 and 2003; Gmehling et al., 1981 and 1988) as well as by the isopiestic method (Scatchard et al., 1938) and with an AquaLab water activity meter similar to the one used in the present study (Ninni et al., 2000). The quite diverse quality of the different datasets necessitates a careful data selection. Measurement series with large scatter were considered as less significant. Figure 1a shows the datasets that were judged to be most reliable for the glycerol/water system. The presented data span a temperature range from $25^{\circ}-$ $290^{\circ} \mathrm{C}$. For 2,3-butanediol/water, the literature data is shown in Fig. 1b. All datasets are based on vapour-liquid equilibria under isobaric conditions at the boiling temperature at $60^{\circ}-$ $180^{\circ} \mathrm{C}$ except the one from Borghesani et al. (1989), which was measured with a vapour pressure osmometer at $25^{\circ} \mathrm{C}$. It can be seen that there is quite a large scatter in some datasets and considerable deviations between datasets.

The data from this study show very good agreement with literature values in the case of glycerol/water, see Fig. 1. For 2,3-butanediol/water they exhibit lower water activities for a given mass concentration than most other datasets, but are in good agreement with Borghesani et al. (1989), whose measurements are however restricted to dilute solutions. In general, water activity measurements by the isopiestic method or with the AquaLab water activity meter are quite accurate 
Table 2. UNIFAC group interaction parameters $a_{m n}$ between groups $m$ and $n$.

\begin{tabular}{lccc}
\hline \multicolumn{4}{c}{$a_{m n}$ (Hansen et al., 1991) } \\
\hline & $\mathrm{CH}_{n}$ & $\mathrm{OH}$ & $\mathrm{H}_{2} \mathrm{O}$ \\
\hline $\mathrm{CH}_{n}$ & 0.0 & 986.5 & 1318 \\
$\mathrm{OH}$ & 156.4 & 0.0 & 353.5 \\
$\mathrm{H}_{2} \mathrm{O}$ & 300.0 & -229.1 & 0.0 \\
\hline
\end{tabular}

\begin{tabular}{lccc}
\hline \multicolumn{4}{c}{$\begin{array}{c}a_{m n} \text { (Ming and Russell, 2002, } \\
\text { parameters for monosaccharides) }\end{array}$} \\
\hline & $\mathrm{CH}_{n}$ & $\mathrm{OH}$ & $\mathrm{H}_{2} \mathrm{O}$ \\
\hline $\mathrm{CH}_{n}$ & 0.0 & 986.5 & 1318 \\
$\mathrm{OH}$ & 156.4 & 0.0 & -189.7 \\
$\mathrm{H}_{2} \mathrm{O}$ & 300.0 & 171.3 & 0.0 \\
\hline
\end{tabular}

\begin{tabular}{lccccc}
\hline \multicolumn{7}{c}{$a_{m n}$ (this study) } \\
\hline & $\mathrm{CH}_{n}$ with -OH group & $\mathrm{CH}_{n}$ in hydrophobic tails & $\mathrm{CH}_{n}$ in alcohols & $\mathrm{OH}$ & $\mathrm{H}_{2} \mathrm{O}$ \\
\hline $\mathrm{CH}_{n}$ with -OH group & 0.0 & 0.0 & 0.0 & 986.5 & 2314 \\
$\mathrm{CH}_{n}$ in hydrophobic tails & 0.0 & 0.0 & 0.0 & 986.5 & 1325 \\
$\mathrm{CH}_{n}$ in alcohols & 0.0 & 0.0 & 0.0 & 986.5 & 1890 \\
\hline $\mathrm{OH}$ & 156.4 & 156.4 & 156.4 & 0.0 & 276.4 \\
$\mathrm{H}_{2} \mathrm{O}$ & -89.71 & 362.1 & 162.3 & -153.0 & 0.0 \\
\hline
\end{tabular}

(Ninni et al., 2000). In comparison, vapour-liquid equilibrium data at the boiling temperature tend to have larger errors especially when one component exhibits a low but not negligible concentration in the gas phase, as it is the case for most polyols in this study. Based on the good agreement for glycerol/water with literature values, and because there is no obvious reason why the accuracy should be worse for other polyols, we assume that the data from this study are accurate within $\pm 0.015 a_{w}$ as specified for the AquaLab water activity meter with the volatile sample block.

Figure 2 shows a comparison of the water activities for the investigated diol/water systems as measured in this work. In aqueous solutions with the same mass concentration, diols with lower molecular weight lead to lower water activities than those with higher molecular weights. This trend is a consequence of both, the growing molecular weight and the increased hydrophobicity of the larger chain diols - the hydrophobicity increase being the dominant factor, as can be seen by comparing Fig. 2a with b. For the diols with four or more carbon atoms, there are also considerable differences between isomers. The 1,2-isomers consisting of molecules with a hydrophilic and a hydrophobic part bind less strongly to water than the other isomers with a more balanced distribution of the hydroxyl groups.

\subsection{UNIFAC predictions}

Figure 3 shows the experimental data and UNIFAC predictions for the investigated butanol/water mixtures. Experimental data from vapour-liquid equilibria at the boiling temperature at $25^{\circ}-35^{\circ} \mathrm{C}$ and under isobaric conditions at 700 $760 \mathrm{mmHg}$ corresponding to a temperature range from 80 to $120^{\circ} \mathrm{C}$ are shown. There is no temperature dependence sufficiently strong to exceed the scatter between various measurements of the inspected alcohol/water vapour-liquid equilibria. The parameters for the UNIFAC predictions at $25^{\circ}$ and $100^{\circ} \mathrm{C}$ are listed in Tables 1 and 2. The UNIFAC parameterization is in good agreement with the experimental data for all butanols but tert-butanol, for which the water activity is overestimated (Fig. 3d). UNIFAC predicts a moderate temperature dependence with stronger water activity depression at higher temperatures.

Figure 4 shows the experimental data and UNIFAC predictions for the investigated pentanediol/water mixtures. For these mixtures, no literature data are available except for 1,5-pentanediol in the more dilute region (Borghesani et al., 1989). The UNIFAC prediction at $25^{\circ} \mathrm{C}$ is in fair agreement with the measurements for 1,2-pentanediol, whereas for all other pentanediols the water activity at a given concentration is clearly overestimated. Figure 4 also shows the water activities for the UNIFAC parameterization by Ming and Russell (2002) with parameters specifically developed 
Table 3. Water activities of the investigated polyol/water mixtures at $25^{\circ} \mathrm{C}$. Concentrations are given in mole fraction of water $x\left(\mathrm{H}_{2} \mathrm{O}\right)$. A star $(*)$ marks values corrected for water content of substance as purchased.

\begin{tabular}{|c|c|c|c|c|c|c|c|}
\hline \multicolumn{2}{|c|}{ Ethanediol } & \multicolumn{2}{|c|}{ Glycerol* } & \multicolumn{2}{|c|}{ 1,2-Propanediol } & \multicolumn{2}{|c|}{ 1,3-Propanediol } \\
\hline$x\left(\mathrm{H}_{2} \mathrm{O}\right)$ & $a_{w}$ & $x\left(\mathrm{H}_{2} \mathrm{O}\right)$ & $a_{w}$ & $x\left(\mathrm{H}_{2} \mathrm{O}\right)$ & $a_{w}$ & $x\left(\mathrm{H}_{2} \mathrm{O}\right)$ & $a_{w}$ \\
\hline 0.0557 & 0.048 & 0.1078 & 0.113 & 0.0796 & 0.083 & 0.0755 & 0.072 \\
\hline 0.1104 & 0.097 & 0.1977 & 0.167 & 0.1699 & 0.174 & 0.1687 & 0.16 \\
\hline 0.1789 & 0.152 & 0.3189 & 0.255 & 0.2753 & 0.285 & 0.2795 & 0.27 \\
\hline 0.2997 & 0.258 & 0.4144 & 0.346 & 0.3635 & 0.38 & 0.3661 & 0.362 \\
\hline 0.3956 & 0.354 & 0.5171 & 0.448 & 0.4330 & 0.436 & 0.4403 & 0.441 \\
\hline 0.4680 & 0.427 & 0.6053 & 0.545 & 0.5248 & 0.54 & 0.5318 & 0.537 \\
\hline 0.5530 & 0.511 & 0.6880 & 0.636 & 0.5938 & 0.604 & 0.6015 & 0.608 \\
\hline 0.6300 & 0.593 & 0.7615 & 0.726 & 0.6750 & 0.678 & 0.6805 & 0.687 \\
\hline 0.6991 & 0.665 & 0.8094 & 0.783 & 0.7399 & 0.742 & 0.7439 & 0.753 \\
\hline 0.7580 & 0.737 & 0.8500 & 0.837 & 0.7953 & 0.79 & 0.7997 & 0.808 \\
\hline 0.8078 & 0.79 & 0.8853 & 0.88 & 0.8547 & 0.847 & 0.8535 & 0.862 \\
\hline 0.8600 & 0.845 & 0.9204 & 0.929 & 0.9078 & 0.91 & 0.9044 & 0.914 \\
\hline 0.9140 & 0.915 & 0.9479 & 0.956 & 0.9572 & 0.961 & 0.9559 & 0.964 \\
\hline \multirow[t]{2}{*}{0.9610} & 0.969 & 0.9678 & 0.975 & & & & \\
\hline & & 0.9864 & 0.988 & & & & \\
\hline \multicolumn{2}{|c|}{ 1,2-Butanediol* } & \multicolumn{2}{|c|}{ 1,3-Butanediol } & \multicolumn{2}{|c|}{ 1,4-Butanediol } & \multicolumn{2}{|c|}{ 2,3-Butanediol } \\
\hline$x\left(\mathrm{H}_{2} \mathrm{O}\right)$ & $a_{w}$ & $x\left(\mathrm{H}_{2} \mathrm{O}\right)$ & $a_{w}$ & $x\left(\mathrm{H}_{2} \mathrm{O}\right)$ & $a_{w}$ & $x\left(\mathrm{H}_{2} \mathrm{O}\right)$ & $a_{w}$ \\
\hline 0.1078 & 0.159 & 0.0838 & 0.099 & 0.1153 & 0.134 & 0.0864 & 0.113 \\
\hline 0.1943 & 0.269 & 0.1523 & 0.176 & 0.2021 & 0.226 & 0.1574 & 0.2 \\
\hline 0.2746 & 0.379 & 0.2497 & 0.29 & 0.2877 & 0.327 & 0.2619 & 0.332 \\
\hline 0.3574 & 0.479 & 0.3357 & 0.394 & 0.3663 & 0.418 & 0.3454 & 0.425 \\
\hline 0.4475 & 0.582 & 0.4062 & 0.471 & 0.4271 & 0.485 & 0.4145 & 0.496 \\
\hline 0.5387 & 0.67 & 0.4738 & 0.54 & 0.4953 & 0.559 & 0.4847 & 0.563 \\
\hline 0.6192 & 0.742 & 0.5482 & 0.609 & 0.5633 & 0.626 & 0.5588 & 0.627 \\
\hline 0.6853 & 0.791 & 0.6171 & 0.671 & 0.6311 & 0.69 & 0.6284 & 0.685 \\
\hline 0.7416 & 0.832 & 0.6948 & 0.742 & 0.6915 & 0.746 & 0.6998 & 0.744 \\
\hline 0.8096 & 0.871 & 0.7669 & 0.802 & 0.7529 & 0.798 & 0.7682 & 0.797 \\
\hline 0.8770 & 0.915 & 0.8325 & 0.854 & 0.8138 & 0.846 & 0.8327 & 0.843 \\
\hline 0.9287 & 0.942 & 0.9098 & 0.926 & 0.8627 & 0.887 & 0.9096 & 0.916 \\
\hline 0.9619 & 0.976 & 0.9661 & 0.976 & 0.9062 & 0.924 & 0.9670 & 0.971 \\
\hline \multirow[t]{3}{*}{0.9843} & 0.992 & & & 0.9379 & 0.953 & & \\
\hline & & & & 0.9627 & 0.97 & & \\
\hline & & & & 0.9802 & 0.986 & & \\
\hline \multicolumn{2}{|c|}{ 1,2-Pentanediol* } & 1,4-Pent & hediol* & 1,5-Pent & hediol* & 2,4-Pen & hediol* \\
\hline$x\left(\mathrm{H}_{2} \mathrm{O}\right)$ & $a_{w}$ & $x\left(\mathrm{H}_{2} \mathrm{O}\right)$ & $a_{w}$ & $x\left(\mathrm{H}_{2} \mathrm{O}\right)$ & $a_{w}$ & $x\left(\mathrm{H}_{2} \mathrm{O}\right)$ & $a_{w}$ \\
\hline 0.1277 & 0.199 & 0.1532 & 0.204 & 0.0951 & 0.137 & 0.1349 & 0.189 \\
\hline 0.2118 & 0.342 & 0.2330 & 0.315 & 0.1819 & 0.245 & 0.2289 & 0.32 \\
\hline 0.2871 & 0.452 & 0.3055 & 0.408 & 0.2585 & 0.359 & 0.3009 & 0.422 \\
\hline 0.3548 & 0.544 & 0.3697 & 0.485 & 0.3250 & 0.444 & 0.3709 & 0.509 \\
\hline 0.4095 & 0.61 & 0.4253 & 0.545 & 0.3850 & 0.516 & 0.4343 & 0.582 \\
\hline 0.4753 & 0.687 & 0.4935 & 0.616 & 0.4538 & 0.595 & 0.4997 & 0.649 \\
\hline 0.5419 & 0.762 & 0.5590 & 0.675 & 0.5329 & 0.676 & 0.5550 & 0.699 \\
\hline 0.6027 & 0.817 & 0.6396 & 0.75 & 0.6130 & 0.754 & 0.6226 & 0.755 \\
\hline 0.6778 & 0.866 & 0.7062 & 0.801 & 0.6792 & 0.806 & 0.6996 & 0.806 \\
\hline 0.7463 & 0.907 & 0.7759 & 0.843 & 0.7489 & 0.85 & 0.7825 & 0.853 \\
\hline 0.8288 & 0.933 & 0.8438 & 0.886 & 0.8203 & 0.891 & 0.8576 & 0.895 \\
\hline 0.9188 & 0.966 & 0.9116 & 0.93 & 0.8957 & 0.933 & 0.9110 & 0.928 \\
\hline 0.9638 & 0.976 & 0.9596 & 0.972 & 0.9535 & 0.967 & 0.9499 & 0.96 \\
\hline 0.9852 & 0.989 & 0.9813 & 0.986 & 0.9784 & 0.982 & 0.9817 & 0.987 \\
\hline 1,2-Неxa & ediol* & $2,5-\mathrm{Hex}$ & ediol* & 1,7-Hep & nediol* & $1,2,4-\mathrm{Bu}$ & netriol* \\
\hline$x\left(\mathrm{H}_{2} \mathrm{O}\right)$ & $a_{w}$ & $x\left(\mathrm{H}_{2} \mathrm{O}\right)$ & $a_{w}$ & $x\left(\mathrm{H}_{2} \mathrm{O}\right)$ & $a_{w}$ & $x\left(\mathrm{H}_{2} \mathrm{O}\right)$ & $a_{w}$ \\
\hline 0.1553 & 0.281 & 0.1570 & 0.214 & 0.1524 & 0.256 & 0.1510 & 0.119 \\
\hline 0.2548 & 0.442 & 0.2491 & 0.346 & 0.2399 & 0.419 & 0.2496 & 0.177 \\
\hline 0.3366 & 0.568 & 0.3352 & 0.463 & 0.3259 & 0.552 & 0.3818 & 0.297 \\
\hline 0.4047 & 0.659 & 0.4136 & 0.558 & 0.4001 & 0.641 & 0.4732 & 0.386 \\
\hline 0.4636 & 0.734 & 0.4790 & 0.625 & 0.4633 & 0.733 & 0.5469 & 0.465 \\
\hline 0.5195 & 0.797 & 0.5634 & 0.716 & 0.5215 & 0.795 & 0.6237 & 0.551 \\
\hline 0.5688 & 0.85 & 0.6341 & 0.774 & 0.5885 & 0.861 & 0.6952 & 0.637 \\
\hline 0.6211 & 0.891 & 0.7184 & 0.834 & 0.6398 & 0.897 & 0.7520 & 0.705 \\
\hline 0.6866 & 0.938 & 0.8018 & 0.878 & 0.7046 & 0.937 & 0.8029 & 0.772 \\
\hline 0.7489 & 0.965 & 0.8785 & 0.92 & 0.7823 & 0.973 & 0.8491 & 0.828 \\
\hline 0.8249 & 0.982 & 0.9317 & 0.951 & 0.8830 & 0.987 & 0.8906 & 0.878 \\
\hline 0.9089 & 0.988 & 0.9675 & 0.98 & & & 0.9242 & 0.921 \\
\hline & & & & & & 0.9509 & 0.951 \\
\hline & & & & & & 0.9731 & 0.975 \\
\hline & & & & & & 0.9860 & 0.989 \\
\hline
\end{tabular}


Table 4. Literature data used for the determination of the UNIFAC group interaction parameters.

\begin{tabular}{lccccl}
\hline Substance & $\begin{array}{c}\text { Number of } \\
\text { data points }\end{array}$ & $\begin{array}{c}\text { Temperature } \\
\left({ }^{\circ} \mathrm{C}\right)\end{array}$ & $\begin{array}{c}\text { Pressure } \\
(\mathrm{mmHg})\end{array}$ & $\begin{array}{c}\text { Fugacity } \\
\text { correction }\end{array}$ & References \\
\hline Ethanol & 15 & 25.13 & $24-60$ & yes & Gmehling and Onken (2003, p. 223) \\
1-propanol & 11 & 25 & $26-35$ & yes & Gmehling and Onken (2003, p. 408) \\
2-propanol & 12 & $80-94$ & 760 & yes & Gmehling and Onken (1977, p. 317) \\
1-butanol & 10 & $93-101$ & 760 & yes & Gmehling and Onken (1977, p. 406) \\
& 3 & $103-113$ & 700 & yes & Gmehling et al. (1981, p. 334) \\
& 5 & $95-99$ & 759.81 & yes & Gmehling and Onken (2003, p. 575) \\
2-butanol & 8 & 25 & $28-33$ & yes & Gmehling and Onken (2003, p. 586) \\
& 8 & $87-95$ & 759.81 & yes & Gmehling and Onken (2003, p. 587) \\
Isobutanol & 14 & $90-107$ & 760 & yes & Gmehling and Onken (1977, p. 439) \\
tert-butanol & 2 & 25 & $27-37$ & yes & Gmehling et al. (1981, p. 343) \\
& 13 & $79-84$ & 760 & yes & Gmehling and Onken (2003, p. 618) \\
1-pentanol & 19 & $95-138$ & 760 & no & Gmehling et al. (1988, p. 309) \\
3-met-1-butanol & 6 & $95-109$ & 760 & no & Gmehling et al. (1988, p. 308) \\
1-hexanol & 6 & 21 & $6-19$ & no & Gmehling et al. (1981, p. 422) \\
Cyclohexanol & 13 & 90 & $104-560$ & no & Gmehling and Onken (1977, p. 514) \\
\hline
\end{tabular}

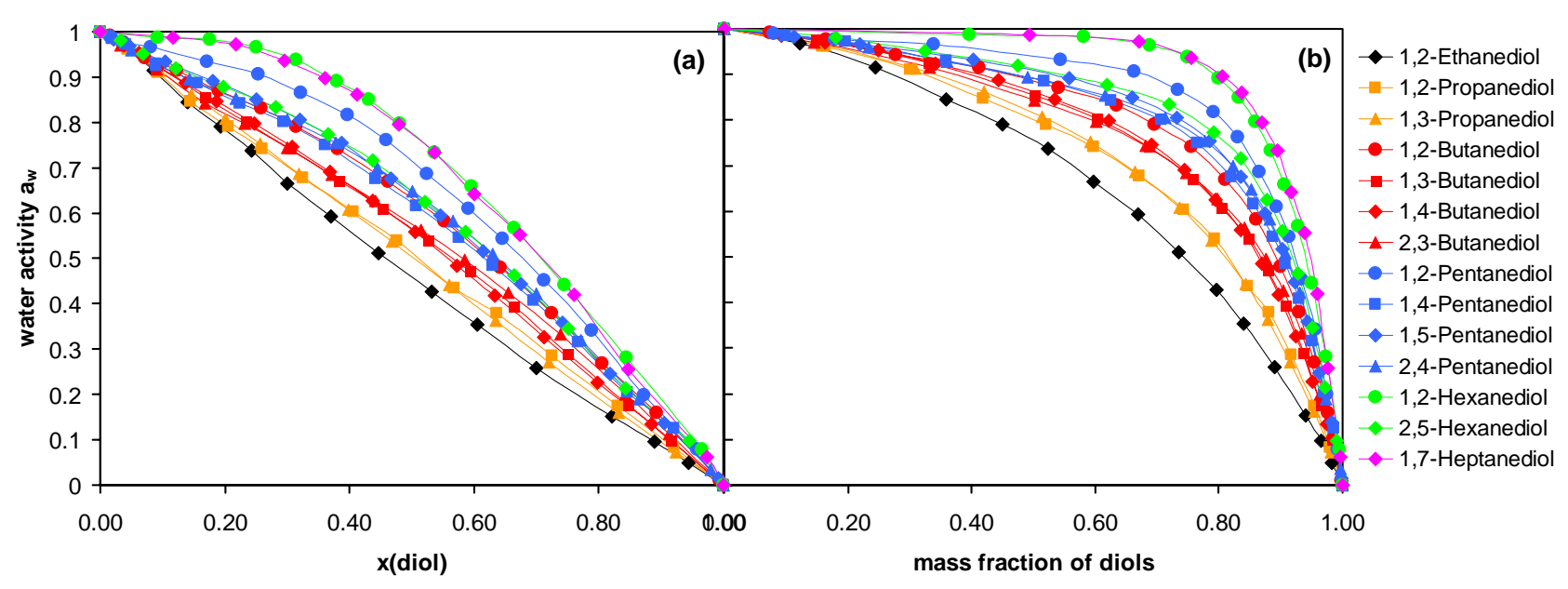

Fig. 2. Measured water activities of the investigated diols at $25^{\circ} \mathrm{C}$ in mole fraction (a) and in mass fraction scale (b).

for monosaccharides as listed in Table 2. This parameterization is in better agreement with the experimental data as the standard UNIFAC, but it can not account for differences between isomers.

UNIFAC predictions are also shown in Fig. 1 for glycerol and 2,3-butanediol/water mixtures. The Ming and Russell parameterization leads to an excellent agreement for glycerol, but overall the UNIFAC parameterizations are limited by the fact that they do not account for differences between isomers (Sandler, 1994).

\subsection{New UNIFAC parameterization}

In UNIFAC, alkyl groups, whether connected to another alkyl group or to a hydroxyl group, are treated the same way. Such a simple parameterization requires only a low number of structural groups, however, can not represent interactions between adjacent atoms in a molecule. UNIFAC does for example not account for proximity effects that occur when two or more strongly polar groups are located on the same or adjacent carbon atoms (Sandler, 1994). One way to overcome this limitation is to define parameters that are specific for certain compound classes. Such parameterizations have been proposed by Peng et al. (2001) for dicarboxylic and hydroxyl-carboxylic acids and by Ninni et al. (1999) for poly(ethylene glycol). Ming and Russell (2002) proposed modified parameterizations for long-chain monofunctional compounds, monosaccharides, hydroxyl-acids and diacids. For polyols (Ninni et al., 2000) and sugars (Peres and Macedo, 1997) modified parameterizations within the UNIFAC-Larsen model (Larsen et al., 1987) have been described. 

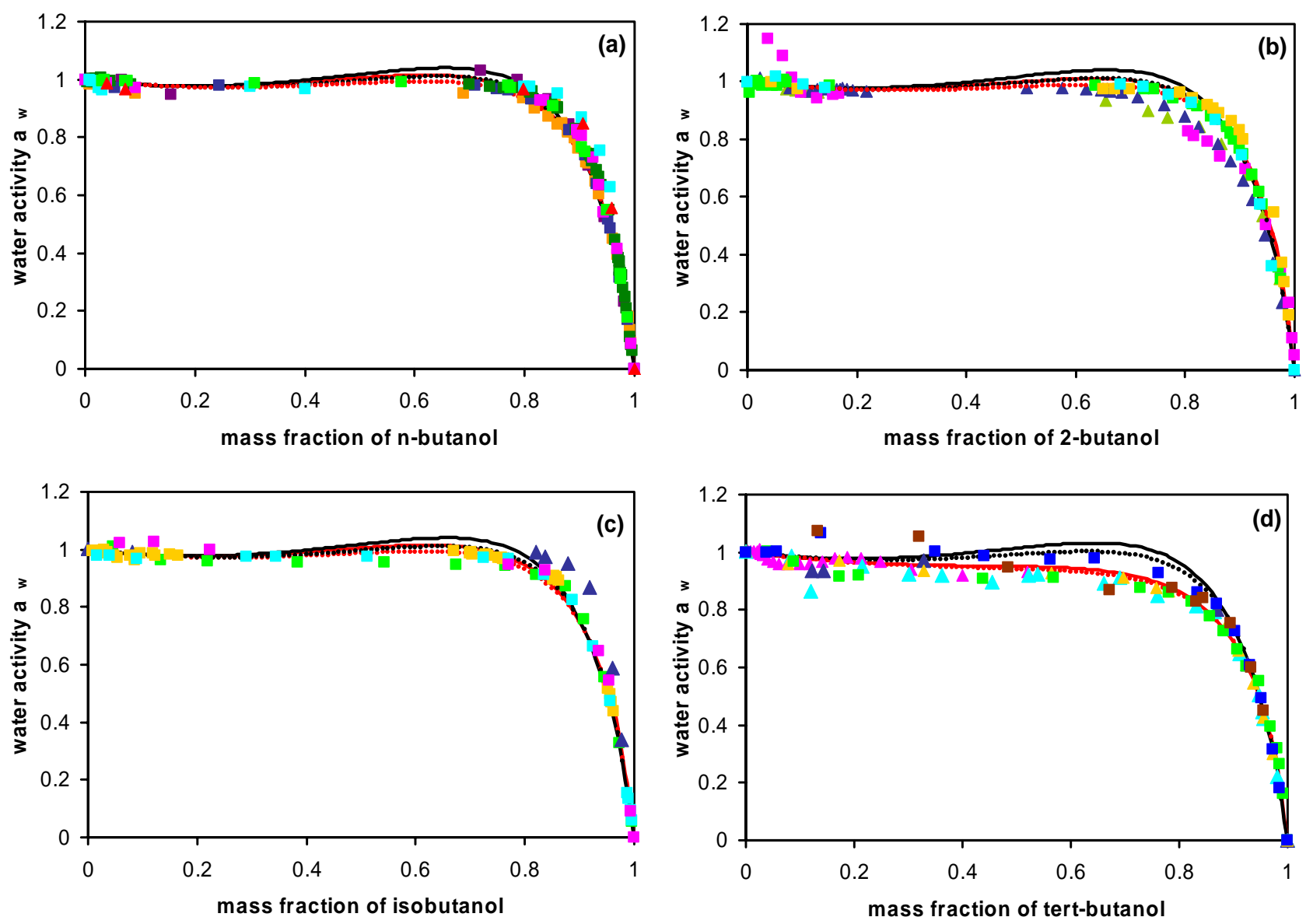

Fig. 3. Water activity of butanol/water mixtures: (a) n-butanol, (b) 2-butanol, (c) isobutanol, (d) tert-butanol. Squares: vapour-liquid equilibrium measurements at constant pressures from $700-767 \mathrm{mmHg}\left(80-120^{\circ} \mathrm{C}\right)$; triangles: vapour-liquid equilibrium measurements at constant temperatures from $25-35^{\circ} \mathrm{C}$, all data taken from Gmehling and Onken $(1977,2003)$ and Gmehling et al. (1981, 1988), different colors indicate different measurement series. Solid lines: UNIFAC predictions at $25^{\circ} \mathrm{C}$, dotted lines: UNIFAC predictions at $100^{\circ} \mathrm{C}$ (black: Hansen et al., 1991; red: using the new parameters from this study).

In this work, a different approach is used: the same group interaction parameters are applied to monofunctional alcohols as well as polyols, however, to improve the accuracy, more specific structural groups are defined. The aim of this new UNIFAC parameterization is therefore twofold: (i) to refine the definition of alkyl groups by accounting for their positions in the molecules; (ii) to adjust group interaction parameters needed to describe polyols. To reach these two goals, a large dataset is required that includes as many isomers as possible. Besides the water activity data acquired in this study for polyol/water, vapour-liquid equilibria of alcohol/water systems from the literature were also considered. The literature data used for the parameterization covers the temperature range from $20^{\circ}$ to $140^{\circ} \mathrm{C}$ and is listed in Table 4. A fugacity correction (Zemp and Francesconi, 1992; Tsonopoulos, 1974) was applied to smaller alcohols.

The UNIFAC parameterization of alcohol/water systems shows two main weaknesses: it underestimates the water up- take of substances with two or more hydroxyl groups and it can not account for the reduced binding to water of isomers with hydrophobic tails. A new definition of alkyl groups should therefore improve these two shortcomings. Moreover, it should be unambiguous and easy to apply. Different sets of alkyl group definitions were tested by fitting UNIFAC water activities to the experimental data. In order to achieve this, water-alkyl and water-hydroxyl group interaction parameters were varied while keeping other parameters constant (i.e., we kept the alkyl-hydroxyl interaction parameters constant, since we did not want to risk a decreased performance of UNIFAC for alkane/alcohol systems in the absence of water). The UNIFAC volume $\left(R_{k}\right)$ and surface area $\left(Q_{k}\right)$ parameters for the alkyl, hydroxyl and water groups were maintained at the literature values (Hansen et al., 1991) listed in Table 1.

This optimization process led to the definition of the following three types of alkyl groups: 

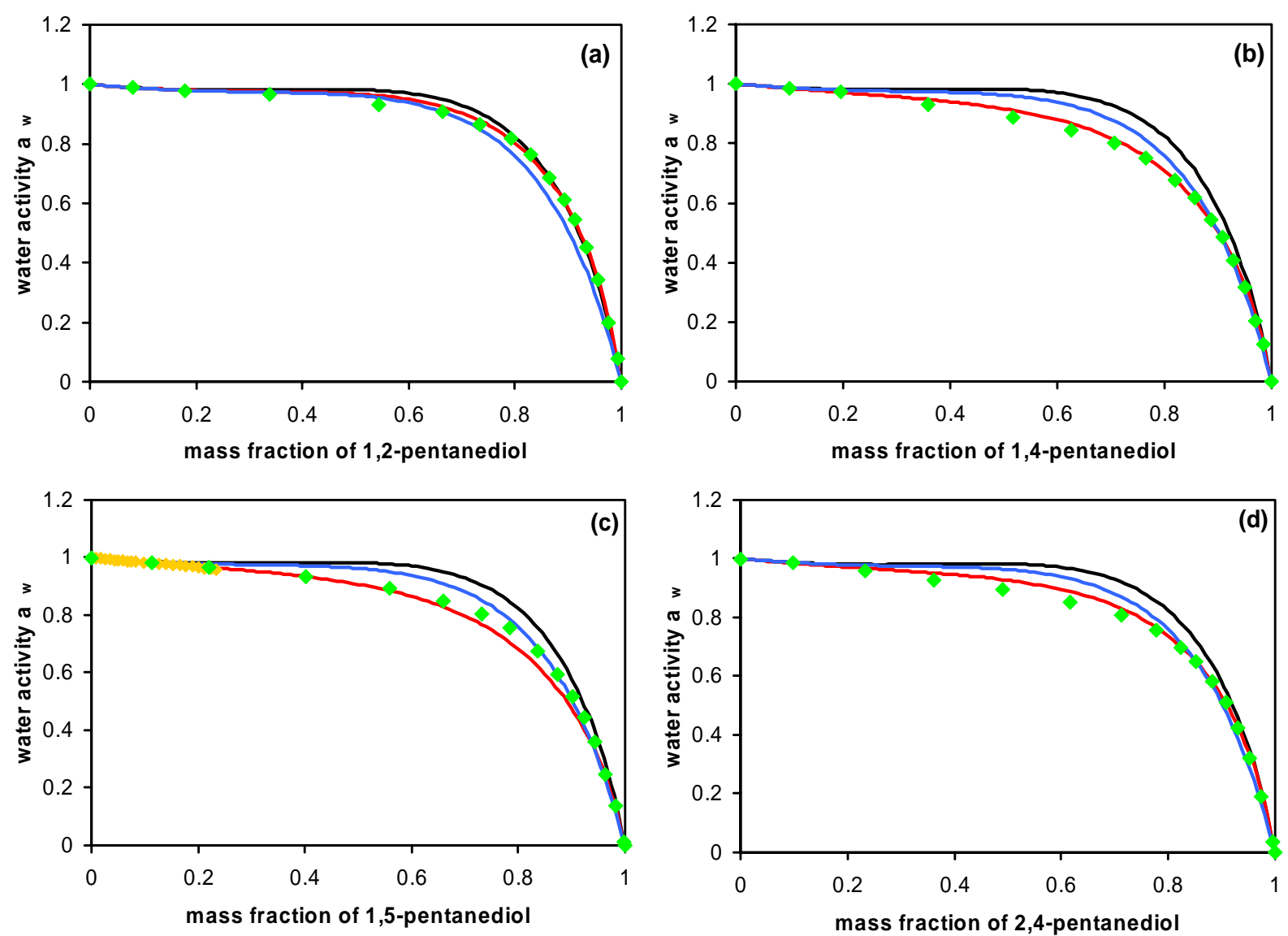

Fig. 4. Water activity of pentanediol/water mixtures at $25^{\circ} \mathrm{C}$ : (a) 1,2-pentanediol, (b) 1,4-pentanediol, (c) 1,5-pentanediol, (d) 2,4pentanediol. Diamonds: water activity measurements at $25^{\circ} \mathrm{C}$ (orange: Borghesani et al., 1989; green: this study). Lines: UNIFAC predictions (black: Hansen et al., 1991; blue: Ming and Russell, 2002; red: using the new parameters from this study).

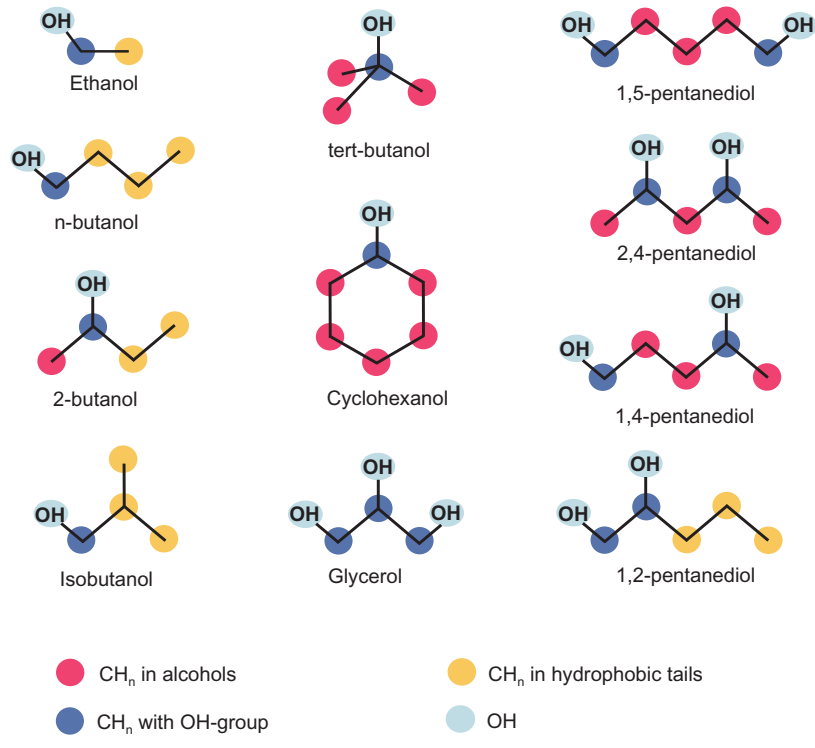

Fig. 5. Examples of the use of the structural groups of alcohols and polyols.
- $\mathrm{CH}_{n}(n=0,1,2)$ with a hydroxyl group: accounts for the induced polarity of alkyl groups directly connected to the electronegative hydroxyl group. This type of alkyl group shows an enhanced interaction with water compared to the other cases.

- $\mathrm{CH}_{n}(n=0,1,2,3)$ in hydrophobic tails: accounts for the non-polar nature of alkyl chains that easily agglomerate and form micelles in water. This type of alkyl group shows decreased interactions with water compared to the other cases. The minimal size of a hydrophobic tail is $-\mathrm{CH}_{2}-\mathrm{CH}_{3}$. As only exception, for ethanol it is $-\mathrm{CH}_{3}$.

- $\mathrm{CH}_{n}(n=0,1,2,3)$ in alcohols: constitutes the general type of alkyl group which applies when the special conditions for the other two types are not fulfilled.

The new group interaction parameters are listed in Table 2 . To exemplify the use of the new definitions several examples are given in Fig. 5. Figures 1, 3 and 4 reveal that the new parameterization is able to account for the observed differences between isomers. The agreement with the experimental water activities for the monofunctional alcohol/water as well as 

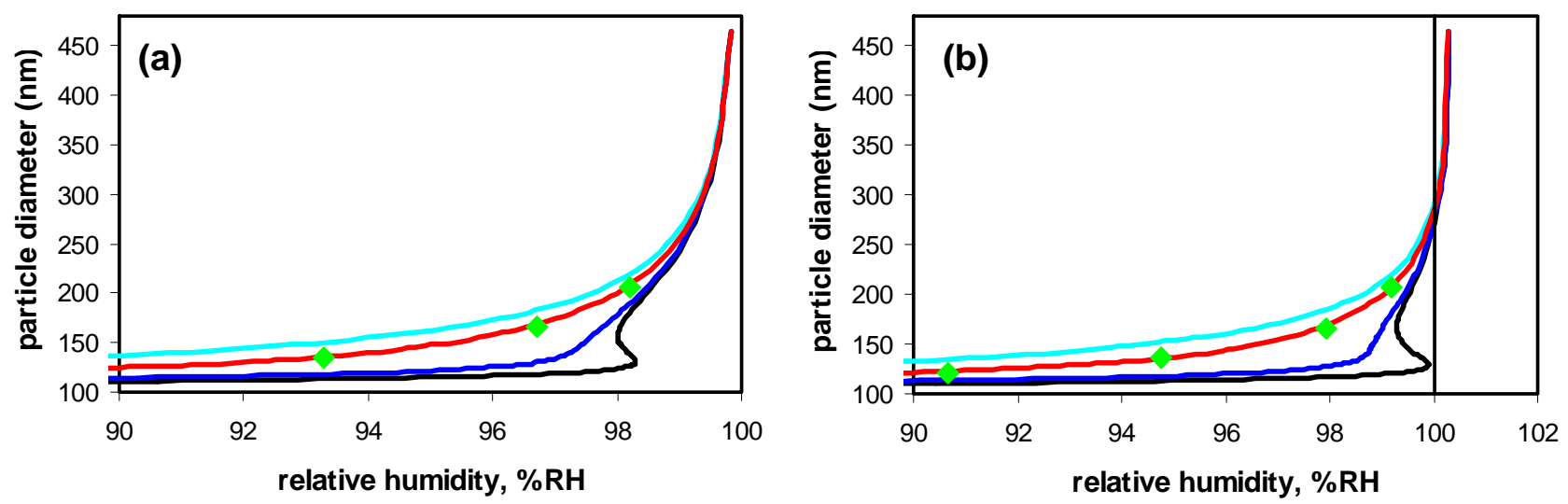

Fig. 6. Hygroscopic growth of 1,5-pentanediol calculated without (a) and with (b) the Kelvin effect. Green diamonds: water activities based on the experimental data; light blue line: ideal conditions $\left(\gamma_{w}=1\right)$. Black line: water activities from standard UNIFAC (Hansen et al., 1991). Dark blue line: water activities from UNIFAC parameterization by Ming and Russell, 2002. Red line: water activities from UNIFAC parameterization of this study.

the polyol/water systems is distinctly improved. For some mixing ratios, the calculated water activity reaches values above 1 in the butanol / water mixtures (Fig. 3), because the UNIFAC prediction was carried out with the premise that the two components are present in the same phase. If the calculations are repeated allowing for the occurrence of phase separations, the new UNIFAC parameterization correctly predicts miscibility gaps for all butanols but tert-butanol, while the parameterization by Hansen et al. (1991) also predicts a phase separation for tert-butanol, which is in disagreement with experimental observations (e.g. Fischer and Gmehling, 1994).

To describe the hygroscopic growth of aerosol particles that may serve as cloud condensation nuclei (CCN), an accurate description of their hygroscopicity at high relative humidities is required. Figure 6 compares the growth characteristics of a $100 \mathrm{~nm}$ diameter particle of 1,5-pentanediol based on model predictions and the experimental data. The UNIFAC parameterization by Hansen et al. (1991) strongly underestimates the water uptake especially for relative humidities between 96-98\%. When the Kelvin effect is included (Fig. 6b), it predicts an increase of only one third in diameter up to almost $100 \% \mathrm{RH}$, whereas the experimental results indicate a duplication of the diameter already at $99 \%$ RH. Interestingly, this substance is much better described by the assumption of solution ideality than by the explicit calculation of water activities based on the standard UNIFAC parameterization. For 1,5-pentanediol, the new parameterization presented in this study is in excellent agreement with the experimental results, enabling the use of UNIFACpredicted water activities to calculate the critical supersaturation for $\mathrm{CCN}$ activation based on Köhler theory (Pruppacher and Klett, 1997).

\section{Conclusion and outlook}

The analysis of an extensive dataset of vapour-liquid equilibrium and water activity data for alcohol/water mixtures showed that the ability of UNIFAC to describe the nonideality of these systems is limited. The main reason for this limitation is due to the fact that the position of the hydroxyl groups in the molecule influences the interactions with water. The definition of structural groups within UNIFAC can not account for such differences. Therefore we developed a new UNIFAC parameterization that discriminates between three types of alkyl groups based on their position in the molecule. This modified UNIFAC model leads to a distinctly improved agreement with experimental data without losing much of the simplicity of the group contribution approach. In future work, this parameterization shall be extended to mixtures containing further functional groups such as carboxylic acid, ether and carbonyl groups with the aim to establish a UNIFAC version that is optimized to describe organic substances of atmospheric relevance and can be implemented in or combined with inorganic thermodynamic models.

Acknowledgements. This work was supported by the Swiss National Foundation under contract No. 2100-063328 and 200020103651/1.

Edited by: M. Ammann 


\section{References}

Bondi, A., Physical properties of molecular crystals, liquids and glasses, Wiley, New York, 450-468, 1968.

Borghesani, G., Pedriali, R., and Pulidori, F.: Solute-solute-solvent interactions in dilute aqueous solutions of aliphatic diols. Excess enthalpies and Gibbs free energies, J. Solution Chem., 18, 289300, 1989.

Bowman, F. M. and Melton, J. A.: Effect of activity coefficient models on predictions of secondary organic aerosol partitioning, J. Aerosol Sci., 35, 1415-1438, 2004.

Cai, X. and Griffin, R. J.: Modeling the formation of secondary organic aerosol in coastal areas: Role of the seasalt aerosol organic layer, J. Geophys. Res., 108(D15), 4440, doi:10.1029/2002JD003053, 2003.

Claeys, M., Wang, W., Ion, A. C., Kourtchev, I., Gelencsér, A., and Maenhaut, W.: Formation of secondary organic aerosols from isoprene and its gas-phase oxidation products through reaction with hydrogen peroxide, Atmos. Environ., 38, 4093-4098, 2004.

Decesari, S., Facchini, M. C., Fuzzi, S., and Tagliavini, E.: Characterization of water-soluble organic compounds in atmosopheric aerosol: A new approach, J. Geophys. Res., 105, 1481-1489, 2000.

Decesari, S., Facchini, M. C., Matta, E., Lettini, F., Mircea, M., Fuzzi, S., Tagliavini, E., and Putaud, J.-P.: Chemical features and seasonal variation of fine aerosol water-soluble organic compounds in the Po Valley, Italy, Atmos. Environ., 35, 3691-3699, 2001.

Erdakos, G. B. and Pankow, J. F.: Gas/particle partitioning of neutral and ionizing compounds to single- and multi-phase aerosol particles. 2. Phase separation in liquid particulate matter containing both polar and low-polarity organic compounds, Atmos. Environ., 38, 1005-1013, 2004.

Fischer, K. and Gmehling, J.: P-x and $\gamma^{\infty}$ data for the different binary butanol-water systems at $50^{\circ} \mathrm{C}, \mathrm{J}$. Chem. Eng. Data, 39, 309-315, 1994.

Fredenslund, A., Jones, R. L., and Prausnitz, J. M.: Groupcontribution estimation of activity coefficients in nonideal liquid mixtures, AIChE J., 21, 1086-1099, 1975.

Fredenslund, A., Gmehling, J., and Rasmussen P.: Vapor-liquid equilibria using UNIFAC, Elsevier, Amsterdam, 1977.

Gao, S., Hegg, D. A., Hobbs, P. V., Kirchstetter, T. W., Magi, B. I., and Sadilek, M.: Water-soluble organic components in aerosols associated with savanna fires in southern Africa: Identification, evolution, and distribution, J. Geophys. Res., 108(D13), 8491, doi:10.1029/2002JD002324, 2003.

Gmehling, J. and Onken, U.: Vapor-liquid equilibrium data collection. Aqueous-organic systems, DECHEMA Chemistry data series, Frankfurt, 1, 1, 1977.

Gmehling, J., Onken, U., and Arlt, W.: Vapor-liquid equilibrium data collection. Aqueous-organic systems, DECHEMA Chemistry data series, Frankfurt, 1, 1a, 1981.

Gmehling, J., Onken, U., and Rarey-Nies, J. R.: Vapor-liquid equilibrium data collection. Aqueous systems, DECHEMA Chemistry data series, Frankfurt, 1, 1b, 1988.

Gmehling, J. and Onken, U.: Vapor-liquid equilibrium data collection. Aqueous systems, DECHEMA Chemistry data series, Frankfurt, 1, 1c, 2003.

Graham, B., Mayol-Bracero, O. L., Guyon, P., Roberts, G. C., Decesari, S., Facchini, M. C., Artaxo, P., Maenhaut, W., Köll,
P., and Andreae, M. O.: Water-soluble organic compounds in biomass burning aerosols over Amazonia 1. Characterization by NMR and GC-MS, J. Geophys. Res., 107(D20), 8047, doi:10.1029/2001JD000336, 2002.

Griffin, R. J., Nguyen, K., Dabdub, D., and Seinfeld, J. H.: A coupled hydrophobic-hydrophilic model for predicting secondary organic aerosol formation, J. Atmos. Chem., 44, 171-190, 2003.

Hansen, H. K., Rasmussen, P., Fredenslund, A., Schiller, M., and Gmehling, J.: Vapor-liquid equilibria by UNIFAC group contribution. 5. Revision and extension, Ind. Eng. Chem. Res., 30, 2352-2355, 1991.

Larsen, B. L., Rasmussen, P., and Fredenslund, A.: A modified UNIFAC group-contribution model for prediction of phase equilibria and heats of mixing, Ind. Eng. Chem. Res., 26, 2274-2286, 1987.

Ming, Y. and Russell, L. M.: Thermodynamic equilibrium of organic-electrolyte mixtures in aerosol particles, AIChE J., 48, 1331-1348, 2002.

Ming, Y. and Russell, L. M.: Organic aerosol effects on fog droplet spectra, J. Geophys. Res., 109, D10206, doi:10.1029/2003JD004427, 2004.

Ninni, L., Camargo, M. S., and Meirelles, A. J. A.: Water activity in poly(ethylene glycol) aqueous solutions, Thermochim. Acta, 328, 169-176, 1999.

Ninni, L., Camargo, M. S., and Meirelles, A. J. A.: Water activity in polyol systems, J. Chem. Eng. Data, 45, 654-660, 2000.

Peng, Ch., Chan, M. N., and Chan, Ch. K.: The hygroscopic properties of dicarboxylic and multifunctional acids: Measurements and UNIFAC predictions, Environ. Sci. Technol., 35, 44954501, 2001.

Peres, A. M. and Macedo, E. A.: A modified UNIFAC model for the calculation of thermodynamic properties of aqueous and nonaqueous solutions containing sugars, Fluid Phase Equilibria, 139, 47-74, 1997.

Pruppacher, H. R. and Klett, J. D.: Microphysics of clouds and precipitation, Kluwer Academic Publishers, Dordrecht, 172-175, 1997.

Pun, B. K., Griffin, R. J., Seigneur, C., and Seinfeld, J. H.: Secondary organic aerosol 2. Thermodynamic model for gas/particle partitioning of molecular constituents, J. Geophys. Res., 107(D17), 4333, doi:10.1029/2001JD000542, 2002.

Roberts, G. C., Artaxo, P., Zhou, J., Swietlicki, E., and Andreae, M. O.: Sensitivity of CCN spectra on chemical and physical properties of aerosol: A case study from the Amazon Basin, J. Geophys. Res., 107(D20), 8070, doi:10.1029/2001JD000583, 2002.

Sandler, S. I. (Ed.): Models for thermodynamic and phase equilibria calculations, New York, Dekker, 287-361, 1994.

Saxena, P., Hildemann, L. M., McMurry P. H., and Seinfeld, J. H.: Organics alter hygroscopic behavior of atmospheric particles, J. Geophys. Res., 100, 18755-18770, 1995.

Saxena, P. and Hildemann, L. M.: Water-soluble organics in atmospheric particles: A critical review of the literature and application of thermodynamics to identify candidate compounds, J. Atmos. Chem., 24, 57-109, 1996.

Saxena P. and Hildemann, L. M.: Water absorption by organics: survey of laboratory evidence and evaluation of UNIFAC for estimating water activity, Environ. Sci. Technol., 31, 3318-3324, 1997. 
Scatchard, G., Hamer, W. J., and Wood, S. E.: Isotonic Solutions. I. The chemical potential of water in aqueous solutions of sodium chloride, potassium chloride, sulfuric acid, sucrose, urea and glycerol at 25, J. Am. Chem. Soc., 60, 3061-3070, 1938.

Simoneit, B. R. T., Kobayashi, M., Mochida, M., Kawamura, K., Lee, M., Lim, H.-J., Turpin, B. J., and Komazaki, Y.: Composition and major sources of organic compounds of aerosol particulate matter sampled during the ACE-Asia campaign, J. Geophys. Res., 109, D19S10, doi:10.1029/2004JD004598, 2004.
Tsonopoulos, C.: An empirical correlation of second virial coefficients, AIChE J., 20, 263-272, 1974.

Yamasoe, M. A., Artaxo, P., Miguel, A. H., and Allen A. G.: Chemical composition of aerosol particles from direct emissions of vegetation fires in the Amazon Basin; water-soluble species and trace elements, Atmos. Environ., 34, 1641-1653, 2000.

Zemp, R. J. and Francesconi, A. Z.: Salt effect on phase equilibria by a recirculating still, J. Chem. Eng. Data, 37, 313-316, 1992. 